\title{
Féeries
}

Études sur le conte merveilleuX, XVII ${ }^{e}$ XIXe siècle

$10 \mid 2013$

Conte et croyance

\section{Le conte mystique du Petit Chaperon rouge : la Bête du Gévaudan et les " inutiles au monde »}

Little Red Riding Hood's Mystical Tale: The Beast of Gévaudan and the

"Unnecessary in the World"

\section{Catherine Velay-Vallantin}

\section{CpenEdition}

Journals

Édition électronique

URL : http://journals.openedition.org/feeries/880

DOI : $10.4000 /$ feeries. 880

ISSN : 1957-7753

Éditeur

UGA Éditions/Université Grenoble Alpes

Édition imprimée

Date de publication : 20 septembre 2013

Pagination : 27-58

ISBN : 978-2-84310-253-0

ISSN : $1766-2842$

\section{Référence électronique}

Catherine Velay-Vallantin, « Le conte mystique du Petit Chaperon rouge : la Bête du Gévaudan et les « inutiles au monde » », Féeries [En ligne], 10 | 2013, mis en ligne le 20 mars 2015, consulté le 08 septembre 2020. URL : http://journals.openedition.org/feeries/880 ; DOI : https://doi.org/10.4000/ feeries. 880 


\section{LE CONTE MYSTIQUE DU PETIT CHAPERON ROUGE : LA BÊTE DU GÉVAUDAN ET LES «INUTILES AU MONDE »}

$U$ NE MODE RÉCENTE a attiré mon attention : de jeunes parents, ayant opté pour un baptême civil, préfèrent, à la robe traditionnelle, un vêtement de Petit Chaperon rouge : "Il n'y a rien de ridicule, c'est son baptême, même s'il n'est pas religieux! On le fait sur le thème du Petit Chaperon rouge, donc robe rouge et blanche, leggins blancs et capecapuchon rouge ${ }^{1}$.» Depuis le début des années 2000, ce n'est pas seulement la robe et le châle de baptême qui se doivent d'être rouges, mais aussi la décoration, les gâteaux, les biscuits et même les dragées... Il est probable qu'attachés à la laïcité, ces parents préfèrent un vêtement qu'ils supposent dépourvu de connotation religieuse, et plus neutre que la traditionnelle robe de lin ou de percale blanche ourlée de dentelle et de guipure. Or, ils se trompent : car précisément, s'il est un conte qui associe une signification religieuse à la coutumière morale d'avertissement, c'est bien le conte du Petit Chaperon rouge. Cette histoire n'a rien de neutre, et encore moins d'irréligieux, bien au contraire.

\section{Un bénitier dans la chambre de la grand-mère}

J'ai pu repérer que depuis le début du $\mathrm{XIX}^{\mathrm{e}}$ siècle, l'iconographie du Petit Chaperon rouge associe des symboles religieux à certaines scènes, en particulier à l'épilogue, lorsque le loup s'apprête à dévorer l'enfant. Premier de cette série d'associations, le tableau de Fleury François Richard, peint vers I820, et acquis récemment par le Louvre en 1995, représente l'ultime scène du conte : le loup vient de dévorer la grand-mère, comme l'atteste la jupe abandonnée à terre, et couché dans le lit, il s’apprête à manger la petite

I. Posté le I2 mai 2012 : <http://forum.doctissimo.fr/famille/bapteme/tenue-bapteme-civilsujet_8346_I.htm>.

Féeries, ${ }^{\circ}$ IO, 2013, p. 27-58. 
fille. La scène est située dans une ancienne église de campagne. Principal représentant de la peinture «troubadour», Fleury Richard a déjà multiplié les petits tableaux de facture hollandaise qui présentent des scènes tirées de l'histoire et de la littérature, situées dans un décor d'église, de cloître ou de crypte à l'éclairage axial ou latéral. Le Petit Chaperon rouge est son dernier tableau puisque, atteint d'une maladie nerveuse, il cesse de peindre en I824. On objectera que Fleury Richard sélectionne délibérément des sujets jugés insignifiants et les installe dans un cadre religieux, pour mieux édifier ou émouvoir sa prestigieuse clientèle, l'impératrice Joséphine et la reine Hortense, pour mieux suivre aussi la mode «médiévaliste» britannique. Le recours à ces motivations ne résout cependant pas l'impression d'angoisse qui sourd de ce tableau, comme si toute compassion divine avait abandonné cette église de campagne, dévastée, peut-on penser, par l'indifférence d'une France postrévolutionnaire. Debout au milieu de ce lieu consacré mais saccagé, l'enfant est bien seule, bien démunie, sa grand-mère l'était tout autant. Notons aussi que c'est la première fois que l'on représente la petite fille habillée d'une capuche rouge, prolongée d'une capeline couvrant les épaules. Cette coupe du chaperon eut, comme on le sait, une longue fortune jusqu'à nos jours.

À la fin du XIX ${ }^{\mathrm{e}}$ siècle, ce sont les abécédaires produits par les imagiers populaires qui associent le plus clairement signes iconiques religieux et conte : ces abécédaires présentent un conte en images à la suite de l'alphabet nécessaire à l'apprentissage de la lecture. Ces histoires en images, qui annoncent la bande dessinée moderne par l'étroite et particulière association du texte et de l'image, ne procèdent ni du livre illustré ni de l'album : la page est découpée en compartiments réguliers sous lesquels peuvent être imprimées quelques lignes de texte. Les compartiments s'enchaînent de gauche à droite et de haut en bas, comme s'il s'agissait de lire un texte en images, et la suite des illustrations produit le récit ${ }^{2}$. Si l'imagier s'attache à combiner l'histoire avec une source narrative connue, le plus souvent des contes et des fables, il reste que l'abécédaire permet de nouvelles recherches de mises en page qui coïncident avec l'ouverture de ses sources d'inspiration : et c'est ainsi que l'enfant, destinataire privilégié, peut se constituer une culture plus autonome. Dans le cas du Petit Chaperon rouge, l'ABC des Enfants Sages, édité par Pellerin en 1874, illustre l'épilogue de la mort de l'enfant par la vignette originelle dont on connaît la longévité, celle dessinée en 1697 par le graveur de Charles Perrault, Clouzier : il n’y a rien

2. S. Le Men, Les Abécédaires français illustrés du XIXe siècle, Paris, Éditions Promodis, I984, p. 39-4I. 
de surprenant à cela. Mais en revanche, produit la même année par Pinot et Sagaire, également à Épinal, et publié à la suite du Nouvel Alphabet de l'enfance orné de gravures et suivi de l'histoire du Chaperon-Rouge, édité en I869 à Metz par C. Thomhs, le Livre des Enfants Sages est nettement plus étrange : il associe une représentation terrifiante du loup, couché dans le lit de la grand-mère, à la présence d'un bénitier accroché au mur de la chambre, surmonté d'un crucifix bien visible et orné du buis bénit du dimanche des Rameaux (figure I).

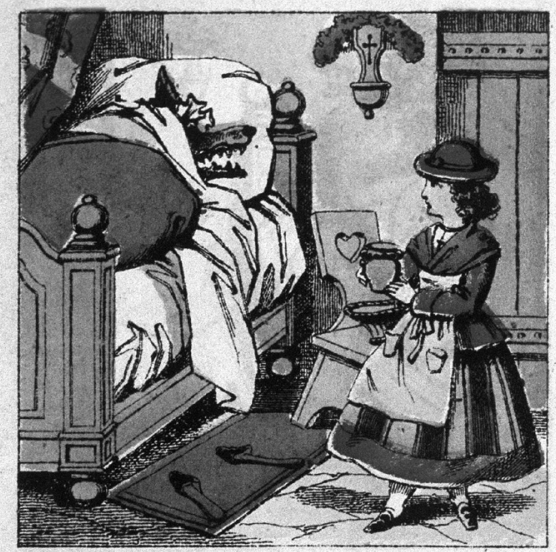

Le petit Chaperon rouge tira la chevillette, la porte s'ouvrit. Le loup la voyant entrer se cacba sous la couverture et lui dit : mets la galette et le pot de beurre sur la huche et viens te coucher avec moi.

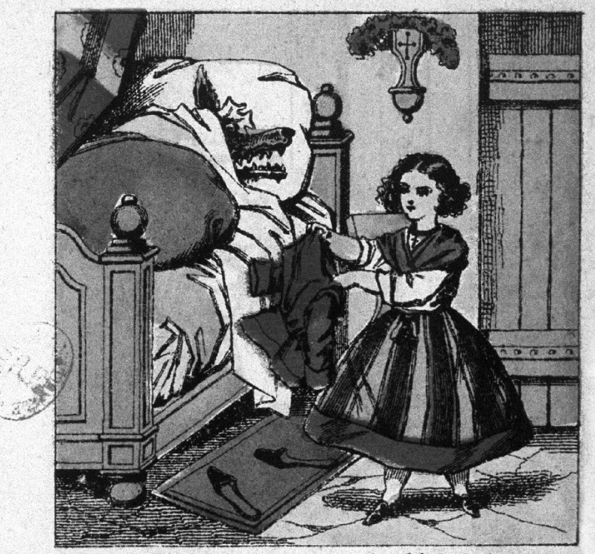

Le petit Chaperon rouge se déshabille et se couche avec le loup.

Figure I : Abécédaire du Petit Chaperon rouge

Chez Pinot et Sagaire, Épinal, 1874

Fonds privé

Dans cette seconde moitié du XIX ${ }^{\mathrm{e}}$ siècle, Épinal demeure seule, avec JeanCharles Pellerin, créatrice de l'industrie de l'image populaire : c'est Pellerin qui comprend le mieux le besoin d'une imagerie enfantine, à la fois instructive et amusante. Il grave lui-même à ses débuts puis engage des graveurs-dessinateurs professionnels, dont Charles Pinot. Après sa mort, Pinot reprend l'affaire, accepte la lithographie nouvellement inventée et multiplie les sujets les plus divers : c'est à lui que l'on doit l'ouverture du fonds Pellerin aux contes et aux légendes. En I860, Pinot fonde avec Sagaire une nouvelle imagerie qui fonctionnera jusqu'en I888. Mais l'ouverture nécessaire à de nouveaux fonds narratifs ne s'accompagne pas forcément d'une complète disparition des attachements idéologiques de la fabrique : si la Révolution 
provoque partout en France la disparition de l'imagerie religieuse et entraîne la destruction des bois gravés et des réserves d'images, les petits imagiers d'Épinal, de Metz, de Nancy, de Montbéliard et de Strasbourg exigent du Concordat de pouvoir continuer à produire des planches hagiographiques, des représentations de la Sainte Famille ou encore des Cantiques. Ils obtiennent enfin l'autorisation de se référer à leur guise à tout sujet ou symbole religieux. Il n'est donc pas innocent que seules parmi les flots de planches distribuées en France, en Europe et même outre-Atlantique, les imageries d'Épinal et Metz rattachent l'univers familial du Petit Chaperon rouge à la religion catholique. Sans doute sont-ils bien rares ceux qui se souviennent qu'au XVII ${ }^{\mathrm{e}}$ siècle, l'imagerie d'Épinal était essentiellement un objet de préservation : les images religieuses, vendues à des colporteurs, étaient découpées, collées à des morceaux de tissus et de papiers coloriés, parfois argentés ou dorés. Une fois collées aux murs, ces images saintes étaient censées protéger les personnes, les biens, les maisons, les bestiaux. Héritières de cet ancien prosélytisme religieux, les gravures de ces abécédaires restituent un décor familier au petit lecteur : la présence d'un crucifix protecteur à la tête de lit d'une grand-mère est alors prescrite comme une évidence.

Au début du Xx ${ }^{\mathrm{e}}$ siècle, c'est un éditeur de littérature enfantine, Henri Laurens, qui publie à Paris en 1900 Les Contes de Perrault, faisant appel à de nombreux illustrateurs réputés, tels que Fraipont, Louis Morin, Robida, Job ou encore Auguste Vimar. Auguste Vimar s'est fait une spécialité de sculptures et d'illustrations animalières; proche de Job et de Robida, il collabore au Figaro illustré et au Rire et a déjà acquis un renom considérable dans le monde de l'édition par ses illustrations des Fables de La Fontaine et de Florian. Il écrit lui-même des livres pour enfants et est sans conteste le dessinateur animalier préféré des éditeurs de livres pour la jeunesse : son talent est tel qu'il influence durablement Benjamin Rabier. C'est donc à Vimar qu'Henri Laurens laisse le soin d'illustrer Le Petit Chaperon rouge: des images au cœur du texte, en sa marge, en bordure ou en encadrement, en pleine page aussi ou encore en cul de lampe... Son inventivité est d'une telle richesse, le trait est si assuré, les expressions des personnages, en particulier du loup, sont si frappantes, que ce conte est de loin le plus réussi du recueil. Il accroche au mur de la chambre de la grand-mère un bénitier, surmonté d'un crucifix, auquel sont suspendus buis bénit et chapelet : l'image apparaît deux fois sur la même page, et son emplacement dans l'encadrement du texte lui confere une sorte de rôle-clé dans ce principe architectural qu'est une mise en page où s'articulent texte et image. La lecture de l'épisode de la dévoration de l'enfant ne peut alors qu'être affectée par la présence imposante de ce crucifix, auquel renvoie sur 
la page opposée l'image effrayante d'un loup féroce (figure 2). Or, Vimar est aussi le dessinateur attitré de la maison d'édition catholique Mame et frères de Tours qui, décidant de mettre l'image au service de la catéchèse, tente depuis les années I88o l'aventure de l'album, genre jusque-là promu par les éditeurs libéraux.
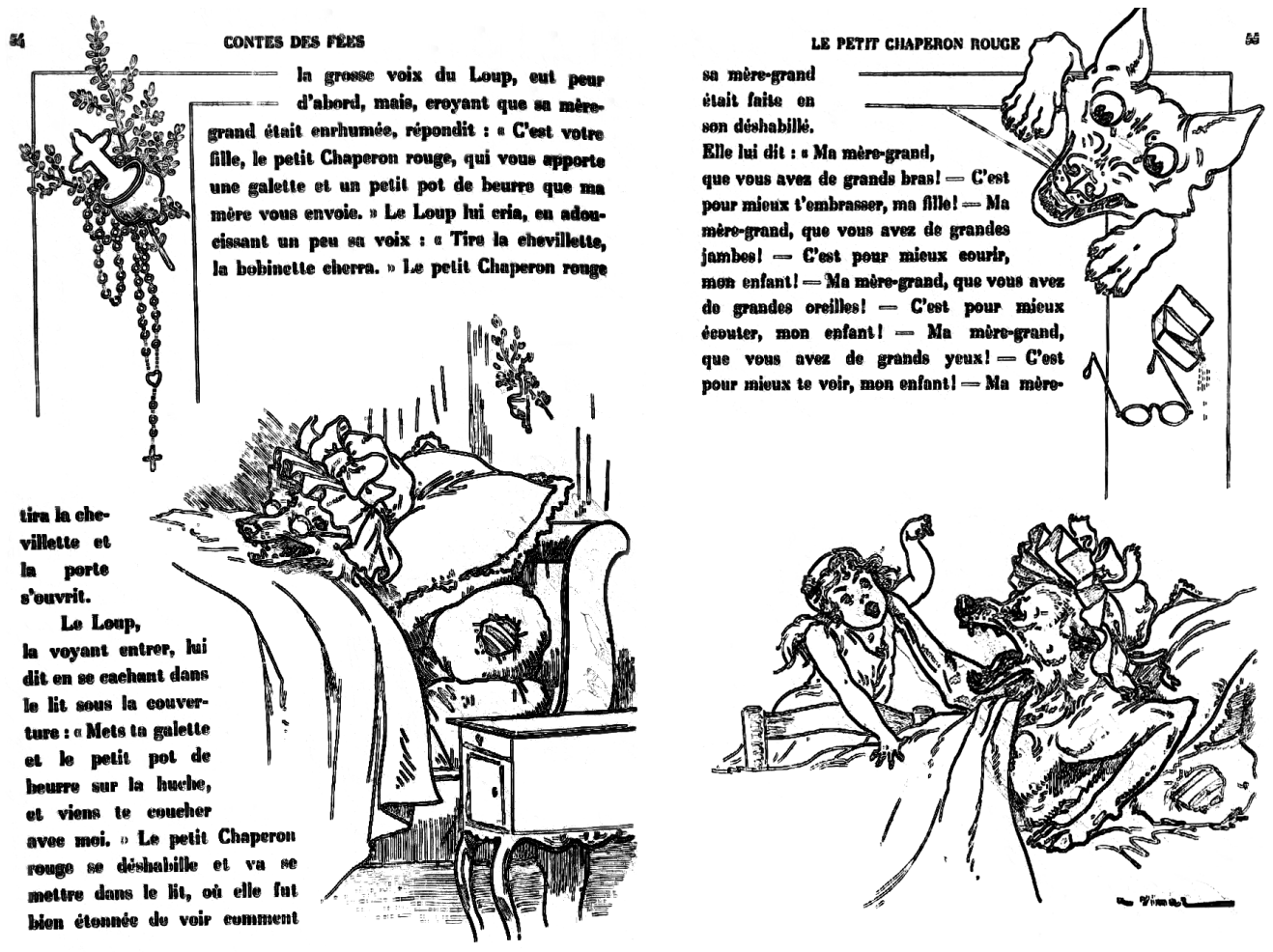

Figure 2 : Les Contes de Perrault

Henri Laurens Éditeur, Paris, 1900 : Le Petit Chaperon rouge,

illustrations d'Auguste Vimar

Fonds privé

\section{Un loup battu à mort}

Ces images ont-elles trouvé leur source dans des récits oraux du conte ou au contraire en ont-elles inspiré? Si des versions concurrentielles, aux compréhensions différentes, ont pu coexister, par quel truchement (éditions populaires ou versions orales indépendantes de celle de Perrault) se sont-elles 
diffusées? Quel contexte a produit cette intelligibilité si particulière du conte, celle qui nous assure qu'aucun crucifix ne peut sauver une grand-mère et sa petite-fille?

Le Petit Chaperon rouge nous est connu pour ses deux épilogues : l'un, malheureux, choisi par Perrault, rapporte que grand-mère et petite fille sont mangées par le loup, sans espoir de secours. Perrault a préféré cette issue pour mieux illustrer la morale d'avertissement qui sanctionne le conte qu'il édite. L'autre, heureux, nous est transmis par la version des frères Grimm : un chasseur délivre du ventre du loup abattu la grand-mère et le Petit Chaperon rouge, étourdies mais vivantes, qui en sont quittes pour la peur.

Les versions orales collectées au XIX ${ }^{\mathrm{e}}$ siècle semblent se partager assez mal entre ces deux épilogues : l'épilogue heureux, quantitativement peu fréquent, subsiste dans le Morvan, la Touraine et les Alpes; il atténue bien évidemment la fonction essentielle de ce conte d'avertissement. L'on ne peut cependant guère déduire quoi que ce soit de ces versions; ce serait faire bon marché de la liberté du conteur : ce dernier en effet varie les destinées heureuses ou malheureuses de ses héroïnes en fonction de son auditoire et de l'impact qu'il veut imprimer sur les esprits, en particulier lorsqu'il y a des enfants dans son entourage. En conséquence, les conditions de collecte de ces versions optimistes nécessiteraient d'être mieux connues, ce qui est souvent difficile lorsqu'il s'agit de collectes de la fin du $\mathrm{XIX}^{\mathrm{e}}$ siècle et du début du $\mathrm{XX}^{\mathrm{e}}$ siècle. De plus, il est difficile de déterminer la part de l'influence de telle ou telle version éditée, celle de Perrault ou celle des frères Grimm, traduite en français dès le XIX ${ }^{\mathrm{e}}$ siècle. Il reste cependant que l'épilogue heureux n'est pas une invention des frères Grimm, mais a bel et bien existé dans l'oralité : la preuve nous en est fournie par une édition de colportage.

En effet, au milieu du XVIII ${ }^{\mathrm{e}}$ siècle, Madame Garnier, éditeur de livrets bleus, à Troyes, publie vers 1750 un recueil : Les Contes des Fées, Avec des Moralités; Par M. Perrault ${ }^{3}$. Les textes sont identiques à ceux de la première édition des Contes, l'édition Barbin de I697. Cependant, les vignettes surplombant les titres viennent de bois réemployés, sans adéquation marquée avec le thème du récit. Seuls deux contes, La Barbe bleue et Cendrillon, sont gratifiés d'illustrations sans ambiguïté. Or, dans ce recueil, la vignette surplombant le titre du Petit Chaperon rouge mérite réflexion : un bois représente l'abattage d'un animal de grande taille, se tenant debout sur ses

3. C. Velay-Vallantin, "Le miroir des contes. Perrault dans les Bibliothèques bleues», dans R. Chartier (dir.), Les Usages de l'imprimé, Paris, Fayard, I987, p. I55-157 et p. I65-168. 
pattes arrière, difficile au premier abord à identifier : est-ce un loup? un âne? un bœuf? Ce qui apparaît certain, c'est que le lecteur ne peut qu'associer cette image au loup dont il va être question tout au long des pages suivantes. Apparemment sans rapport avec l'histoire, cette scène de tuerie fait bien allusion au dénouement connu du cycle folklorique où le loup est exécuté par un chasseur. Confrontée à la cruauté de l'épilogue de Perrault et attachée à l'uniformité des issues heureuses du recueil des Contes, Madame Garnier a ainsi délibérément cherché à atténuer par l'image l'effet de la version choisie par l'Académicien. Une recherche plus précise m'a permis d'identifier ce bois gravé : il s'agit de celui utilisé pour illustrer la fable de La Fontaine, démarquée d'Ésope, L'Âne et le Petit chien. Un âne se met en tête de quémander les mêmes caresses que son maître voue à son petit chien et grimpe sur ses genoux; furieux d'être blessé par les sabots rugueux de l'animal, le maître en appelle à «Martin-bâton » pour le corriger. Pour la première édition lettrée, la gravure sur cuivre, copiée grossièrement des décennies plus tard sur le bois des éditions de colportage, est de François Chauveau, graveur attitré des éditeurs de contes et de fables, tels que Denys Thierry, Claude Barbin et Jean-Baptiste Coignard. Elle est violente et ne fait guère de place à l'indulgence : l'âne y est manifestement battu à mort.

Deux remarques nous viennent à cet instant : il est possible que nous soyons devant un intérêt, mal défini et incertain, mais nouveau, pour le public enfantin. Madame Garnier est peut-être une des premières parmi les éditeurs de la Bibliothèque bleue à anticiper les réactions, les goûts, les attentes de ce public encore mal cerné en France : l'enfant. Elle sait que le livre peut être lu par l'enfant, mais aussi, et plus sûrement, par un adulte qui lira l'histoire à haute voix et qui montrera l'image à son auditoire, enfantin ou non. Il ressort de cet exemple que l'éditeur connaît de façon sûre les protocoles de lecture de sa clientèle et les modalités d'appréhension du sens de ses livres : il sait qu'un lecteur lit un texte autant qu'il le regarde; que l'image donnée à voir peut être porteuse des effets de sens d'un texte antérieur au texte imprimé; que l'oralité, omniprésente dans le bagage culturel du lecteur, peut s'avérer la meilleure source de compréhension d'un récit imprimé qui raconte la même histoire, déjà connue sous d'autres formes, pour d'autres raisons, pour d'autres apprentissages. Car il ne fait guère de doute que cette image rend compte d'un récit parallèle où le loup était tué et la petite fille sauvée. Près de cinquante ans après les premières éditions bleues des Contes de Perrault, l'édition de Madame Garnier révèle que plusieurs récits, aux normes différentes et aux significations contrastées, coexistent dans la mémoire et la compréhension des lecteurs et des auditeurs. Pour ce public habitué au colportage, l'exploration cognitive de 
plusieurs épilogues, contradictoires certes, mais affrontés simultanément, est donc monnaie courante.

Ces quelques exemples restituent une préoccupation lancinante, d'une décennie à l'autre, du milieu du XviII ${ }^{\mathrm{e}}$ siècle au début du $\mathrm{Xx}^{\mathrm{e}}$ : comment sauver la petite fille et la grand-mère? Comment les protéger? Peut-on vraiment espérer qu'un chasseur dont l'intervention n'est due qu'au hasard puisse leur venir en aide? Ne vaudrait-il pas mieux afficher sa confiance en la protection divine? Or, en cette seconde moitié du XviıI ${ }^{\mathrm{e}}$ siècle, un fait-divers violent enseigne que c'est sans espoir : attendre que le Petit Chaperon rouge trouve son salut en manifestant sa foi religieuse s'avère malheureusement vain. Car il existe un «vrai» Petit Chaperon rouge : elle s'appelle Gabrielle Pélissier, elle fut tuée par la Bête du Gévaudan et on disait qu’elle était communiante.

\section{L'histoire de la Bête du Gévaudan}

C'est à l'été I764 que commence l'histoire de la Bête : une fille de quatorze ans est découverte le $\mathrm{I}^{\mathrm{er}}$ juillet, en Gévaudan, près de Saint-Étienne de Ludgarès, à moitié dévorée. Pendant tout l'été, il y aura d'autres victimes, jeunes vachers ou vachères, dévorés non loin de la forêt de Mercoire. La population de ces contrées s'émeut et le capitaine des dragons, Duhamel, en garnison à Langogne, décide de poursuivre cet animal avec une soixante de dragons. Ces premières chasses n'ont aucun résultat sinon, peut-être, de faire fuir cette Bête vers d'autres lieux ${ }^{4}$.

4. L'histoire de la Bête du Gévaudan a donné lieu à de nombreux travaux. Parmi ceux-ci : F. Buffière, La Bête du Gévaudan, une grande énigme de l'histoire, Toulouse, édité chez l'auteur, 1987, rééd. 1990; V. Campion-Vincent, Des fauves dans nos campagnes. Légendes, rumeurs et apparitions, Paris, Imago, I992; G. Crouzet, Quand sonnait le glas au pays de la Bête, Clermont-Ferrand, CRDP, 1985, rééd. 1987 et Requiem en Gévaudan, Clermont-Ferrand, CRDP, I992; F. Fabre, La Bête du Gévaudan, Paris, Librairie Floury, 1930, Édition complétée par Jean Richard, De Borée, Romagnat, 2006; J.-M. Gibert, La Bête du Gévaudan. Les auteurs du XVIII ${ }^{e}, X I X^{e}, X X^{e}$ siècles : historiens ou conteurs?, Mende, Société des Lettres, Sciences et Arts de la Lozère, 1993; R. Mazauric, «Mandement de Mgr. de Choiseul-Beaupré, évêque de Mende", dans Lou Païs, juin 1960; É. Mazel et P.-Y. Garcin, La Bête du Gévaudan à travers 250 images, Marseille, Éditions Gaussen, 2008; G. Ménatory, La Bête du Gévaudan, Mende, Chaptal, I976, rééd. 1984; Abbé P. Pourcher, Histoire de la Bête en Gévaudan, Saint-Martin de Boubaux, Impr. Pourcher, I889, rééd. Paris, Reder, 1979 et Marseille, Laffitte Reprints, I996; H. Pourrat, Histoire fidèle de la Bête en Gévaudan, Paris, Éditions de l'Épervier, 1946 et Marseille, Lafitte reprints, 1982; R. Scohy, La Bête du Gévaudan, Manifestations littéraires et populaires d'un phénomène historique mal connu, Mémoire de licence en philologie romane, Université libre de Bruxelles, 1984-1985; Jay M. Smith, Monsters of the Gévaudan. The Making of a Beast, Harvard University Press, 2011; B. Soulier, Le Loup dans l'imaginaire contemporain du Gévaudan, Mémoire de maîtrise d'ethnologie, Université Paul Valéry-Montpellier III, 1988. 
En effet, l'on va signaler de nouvelles attaques dès l'automne i764 dans une autre partie du Gévaudan, plus vaste, couvrant une grande partie de la Margeride, d'Arzenc de Randon à Saint-Juéry, à la limite de l'Auvergne. L'ordre est alors donné à Duhamel de continuer la chasse et il s'installe dès le mois de novembre à Saint-Chély d'Apcher. De grandes chasses sont alors organisées à l'initiative de Lafont, subdélégué de l'intendant du Languedoc, mobilisant des centaines, voire des milliers de paysans et de chasseurs. Pourtant les attaques de la Bête se poursuivent et l'on compte déjà à la fin de l'année une vingtaine de victimes. À ce moment-là, la peur est grande dans les campagnes et les gazettes commencent à parler de cette fameuse Bête qui «mange le monde en Gévaudan».

Le 3I décembre I764, l'évêque de Mende, Mgr de Choiseul-Beaupré, fait publier dans tout son diocèse un mandement qui sera lu dans les paroisses par les curés : pour l'évêque de Mende, la Bête est envoyée par Dieu pour punir le peuple du Gévaudan.

Au début de 1765, de grandes battues sont menées contre la Bête, malgré le froid et la neige, mais la liste des victimes ne cesse de s'allonger; aussi Louis XV va-t-il confier la direction des chasses à l'un des plus grands chasseurs de loup de l'époque, M. d'Enneval, gentilhomme normand, et à son fils. Les d'Enneval vont donc traquer la Bête au printemps et au début de l'été 1765 , en utilisant tous les moyens connus : affût, chasses à cheval, animaux empoisonnés. Ils reçoivent parfois l'aide de nobles locaux, tel le marquis d'Apcher, et de chasseurs venus de la France entière. Mais ils ne tuent que quelques loups et la Bête continue ses attaques meurtrières du nord du Gévaudan au sud de l'Auvergne. Dans la France entière et à la Cour, on ne cesse de parler de cette Bête du Gévaudan qui semble invulnérable. Louis XV décide d'envoyer alors en Gévaudan son portearquebuse, Antoine, accompagné de son fils, d'une quinzaine de gardeschasse prestigieux et de chiens de la louvèterie royale.

Toute cette armada arrive en Gévaudan le 22 juin 1765 au Malzieu et les chasses reprennent. À ce moment-là, les attaques de la Bête semblent se concentrer davantage entre Gévaudan et Auvergne autour de Saugues et d'Auvers. Un très grand loup est tué le 28 août par l'un des gardes mais les massacres continuent. Antoine commence à désespérer quand on lui signale des ravages causés par des loups dans les bois des Dames de l'Abbaye Royale des Chazes, sur la rive droite de l'Allier. Une chasse est organisée et Antoine tue lui-même le 20 septembre un grand loup que l'on croit être la Bête du Gévaudan. Pendant plus d'un mois, les attaques cessent et Antoine est présenté comme le libérateur du Gévaudan. Il rentre alors à Paris et est accueilli en héros par la Cour. 
Les attaques vont pourtant reprendre au début du mois de décembre 1765 mais, pour la Cour, l'histoire de la Bête s'arrête officiellement le 20 septembre 1765 . En 1766, la Bête fait de nouvelles victimes, notamment autour de Lorcières, mais en nombre beaucoup moins important, en tout cas officiellement. Après la vingtaine de victimes officielles de 1764 , on en compte cinquante-six en 1765 et seulement sept en 1766 . Pendant cette année I766, le subdélégué Lafont est contraint de conduire les chasses avec des moyens limités et l'aide de quelques nobles locaux. L'année 1767 arrive et la liste des victimes s'allonge encore. On en comptera encore seize jusqu'à la fin présumée de la Bête. Les dernières attaques ont lieu sur un territoire plus réduit, près des villages blottis contre le Mont-Mouchet et le MontChauvet, sur la Margeride. Des pèlerinages sont alors organisés à NotreDame d'Estours et à Notre-Dame de Beaulieu pour demander à Dieu la fin des massacres. Finalement le I9 juin 1767, lors d'une chasse menée par le marquis d'Apcher, la Bête du Gévaudan est tuée par un paysan-braconnier, Jean Chastel. L'on suppose qu'il s'agit bien cette fois de la "vraie» Bête car les attaques cessent définitivement.

C'est au cour de ce drame auquel toute une région est soumise que se noue un drame plus spécifique, celui de la mort tragique, en avril 1765 , d'une jeune fille, Gabrielle Pélissier. Comment ce fait-divers sanglant est-il devenu une légende? Quel rapport la légende a-t-elle entretenu avec le conte?

\section{La communiante était en rouge}

Au lendemain de la mort de Gabrielle Pélissier, voici l'acte de sépulture signé du curé de son village, La Clauze, près de Grèzes :

Le septième avril, même année que dessus (1765), a été dévorée par la bette féroce Gabrielle Pelicier, de la Clauze, sur cette paroisse, âgée d'environ dix-sept ans, et les débris ont été enterrez le lendemain au cimetière de cette paroisse tombeau de ses prédécesseurs, présents Jean Cubizole du susdit village et Benoît Bret, clerc qui ont déclaré de sçavoir signer, de ce enquis et requis. De Rochemure, curés.

Mais dès le lendemain de l'enterrement, on réécrit l'histoire et des versions divergentes s'affrontent. L'abbé Pourcher nous les restitue ${ }^{6}:$ le 8 avril, une lettre de La Fageole parle d'

5. Registre de Grèzes. Greffe de Riom (Cour d'Appel) cité par F. Fabre, La Bête du Gévaudan, édition complétée par Jean Richard, ouvr. cité, p. 5I.

6. Abbé P. Pourcher, Histoire de la Bête du Gévaudan, ouvr. cité, p. 467-470. 
une petite fille qui, après avoir fait sa première communion, alla garder ses vaches à la Champ-de-la-Dame, encore vêtue de ses habits rouges. Son père l'accompagna et resta avec elle presque tout le soir; mais peu avant le coucher du soleil, son père lui dit : je ne crois pas que la Bête soit dans l'endroit. Tu diras seule tes prières; je commence de marcher; tu viendras bientôt rentrer. Le père la quitta en l'encourageant. Mais aussitôt que le père eut disparu, la Bête s'approcha de la fille et la tua. Probablement ses vaches voulaient la défendre, car le lendemain on les vit presque toutes tâchées du sang que la Bête leur avait soufflé.

La suite du récit est tout-à-fait curieuse :

Lorsque la Bête l'eut mangée en partie, elle arrangea au milieu d'un bourbier si bien ses os, sa tête coupée, qu'elle couvrit de ses habits rouges, et son chapeau, que quand on vint la chercher, avant qu'il fût nuit, on la crut endormie. La Bête avait disparu.

Une seconde lettre, de Marvejols, le I4 avril, donne des indications différentes : la fille avait seize ans; elle était très jolie. Une de ses sœurs lui tenait compagnie; voyant la Bête la première, elle lui cria : "Prends garde à toi, tu as un gros loup derrière!» Déjà, le loup s'était emparé de Gabrielle. Sa sœur courut, en poussant de hauts cris, au village qui n'était qu'à quelques pas de là. Se retournant, elle vit

la tête de cette aimable sœur tombant par terre, tandis que le corps était encore debout. L'impression que lui fit cet horrible spectacle fut si forte, qu'elle en eut sur le champ l'esprit totalement aliéné. De sorte que voyant accourir les gens que ses premiers cris avaient attirés, elle se mit à fuir d'un autre côté, en leur disant : "Que vous ai-je fait? Pourquoi voulez-vous m'assassiner?” On ne sait si depuis elle est remise ou si son aliénation dure encore.

\section{L'auteur de la lettre ajoute :}

Plusieurs de nos paysans ne croient pas que ce soit une bête, mais quelque diable qui en a pris la figure... Ils la tiennent pour un être subtilement raisonnant, immortel, invulnérable, qu'il faut chasser avec de l'eau bénite.

Quelle version choisir? Et pourquoi ces récits contradictoires émergent-ils aussi rapidement après le décès? Dans un premier temps, examinons les faits : Gabrielle Pélissier a été tuée le 7 avril I765, à La Clauze, dans la paroisse de Grèzes, près de Saugues; or, les dernières attaques de la Bête dans cette paroisse datent du mois de janvier; en revanche, les meurtres des 3, 4, 5 , et 8 avril 1765 se cantonnent dans une autre zone de la Margeride, à une cinquantaine de kilomètres plus au sud, selon un trajet plutôt cohérent : Fontans, Saint-Denis, Arzenc de Randon, Chaudeyrac. La dévoration de Gabrielle Pélissier apparaît donc atypique au sein de ce parcours géographique et chronologique. L'hypothèse d'une agression commise dans la région de Grèzes et de Chanaleilles par un autre loup que celui qui sévit plus 
au sud a été évoquée, fort logiquement ${ }^{7}$. Mais il y a plus : les agressions dans cette région présentent plusieurs particularités. Tout d'abord, contrairement à ce qui se passe en Margeride et sur l'Aubrac, les attaques ne commencent qu'en janvier 1765 et elles sont peu nombreuses : sept sur la soixantaine qui endeuille cette année 1765 . Par ailleurs, ce sont tout d'abord des petits garçons qui sont attaqués. Il est probable que cette région du Gévaudan, délimitée maintenant par la Haute-Loire, réservait à ses filles d'autres activités domestiques que celles de gardiennes de troupeaux, et qu'en conséquence, elles étaient moins exposées que les garçons. Autre singularité : Grèzes et Chanaleilles ont été le théâtre d'actes de bravoure et de lutte héroïque contre la Bête : l'histoire remarquable du combat victorieux de sept enfants conduits par le petit André Portefaix, le I2 janvier I765 à Chanaleilles, est encore racontée de nos jours; le I7 janvier de la même année, c'est à Grèzes qu' «un homme solide qui fait le moulinet avec son fusil " parvient ainsi à mettre le loup en fuite. Dans cette région, moins exposée donc, et qui peut surtout s'enorgueillir de protéger ses filles, l'agression de Gabrielle Pélissier est exceptionnelle, à plusieurs titres.

Les incohérences des récits renforcent le sentiment d'étrangeté que causent les versions divergentes de la tuerie. La première lettre de La Fageole, par exemple, rapporte le témoignage des paysans venus ramener les vaches à l'étable dès le lendemain. Les bêtes s'étaient sans doute rassemblées pour défendre la jeune fille, disent-ils, car elles étaient «éclaboussées du sang de Gabrielle que la Bête leur avait soufflé». Précision impensable : tout paysan sait que devant le danger, les vaches, même les plus domestiquées, s'enfuient le plus loin possible.

Mais les choses n'en sont pas restées là et la réécriture narrative s'amplifie, au point de bâtir sur les premières incohérences une fiction religieuse. Après les lettres, voici donc le temps des complaintes. C'est dès la fin du mois d'avril qu'une complainte anonyme en quatorze quatrains est composée sur la mort de Gabrielle Pélissier :

À l'abri d'une terre close,

Sur le penchant d'un coteau,

Une petite fille de La Clauze,

Gardait ses vaches et ses veaux. [...]

D'une dent furieuse la Bête

Sur la fondrière voisine

Fait craquer les os de la tête,

Lui déchire la poitrine. [...]

7. F. Buffière, ouvr. cité, p. 192-194. 
De ses habits rouges tout est couvert

Et la tête de son chapeau.

Et tout est si bien arrangé

Que de loin paraît endormie.

La complainte suggère une raison à ce trépas effrayant : dans un élan mystique, la jeune fille aurait imploré une mort rapide pour rejoindre au plus vite "Jésus son unique bien " et semble supposer que la prière a été exaucée dans la journée même :

Ah! sans tarder davantage,

Jésus, soyez mon meilleur sort!

Que mon corps, par un naufrage,

Rende mon âme au divin port ${ }^{8}$ !

\section{« Elle était comme si elle venait de naître »}

Le 2I décembre 1765 , une autre jeune fille, Agnès Mourgues est dévorée à Lorcières. L'abbé Ollier en donne la relation suivante :

Agnès Mourgue, âgée d'environ douze ans, gardait les bestiaux dans les communs d'un village de ma paroisse; ainsi la Bête féroce, après avoir combattu avec elle et s'étant défendue avec des pierres et ayant succombé, luy coupa la teste qu'elle transporta à six pas de son corps, le traîna pour en manger tout le col, les épaules, le devant des mamelles, le mollet d'une jambe, après luy avoir tiré ses bas avec ses griffes des pattes de devant, et quelques ouvertures au bas ventre, de sorte que quelques personnes qui gardaient des bestiaux un peu éloignés de là, voyant des bestiaux en déroute, y accoururent sur les lieux, et ils virent l'enfant dévorée, et lorsque l'on fut pour faire l'enterrement, l'on trouva que le monstre avoit tellement mis en pièces et son corps et ses habillemens qu'elle étoit comme si elle venait de naître?.

C'est alors que le libraire Abraham Fontanel produit à Mende un dessin à la plume rehaussé d'aquarelle qui représente l'éventration et la dévoration d'une enfant par la Bête : maladroit et effrayant, ce dessin représente le corps d'un enfant dénudé, ou presque (un linge couvre le sexe), à terre, entre les pattes d'un loup dont la tête et l'échine noires et hérissées, les pattes crochues, signent la sauvagerie. Le loup laboure le ventre de l'enfant et dévore son bras, du sang se répand à terre. Un examen plus attentif révèle qu'il s'agit d'une fille, l'arrondi des seins est appuyé. En opposition aux autres estampes qui ont proliféré depuis 1764, l'image montre un loup sexué : un pénis et des testicules lui sont dessinés, d'un noir tranchant sur le roux du

8. Abbé P. Pourcher, ouvr. cité, p. 47I-473.

9. Abbé Ollier, Archives du Puy de Dôme, C. 1738, cité par F. Fabre, ouvr. cité, p. I37-I38. 
pelage, rappelant le noir de la tête et de l'échine ${ }^{\text {Io }}$. La troublante violence de cette image, suscitée par la nudité de cette enfant à peine pubère et par la posture du loup sur son corps offert à la dévoration, s'offre en écho d'une lecture sexuelle de l'agression d'Agnès Mourgues (figure 3).

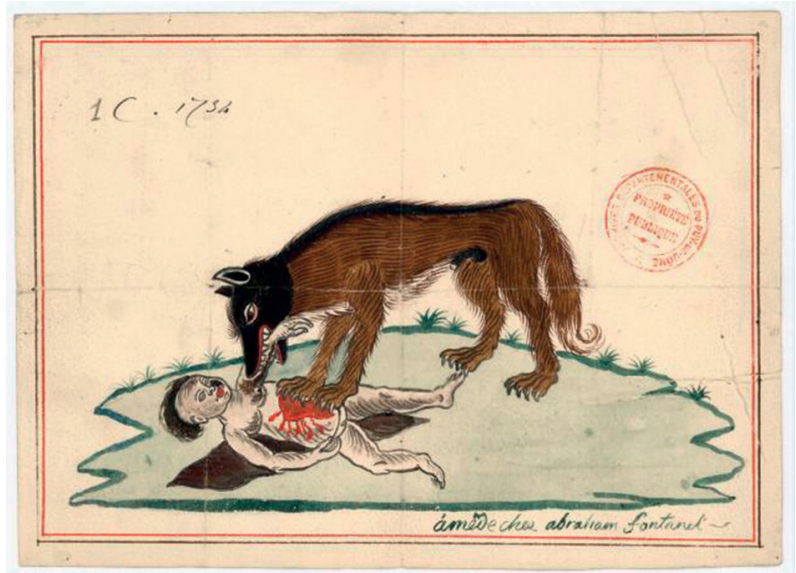

Figure 3 : Dessin rehaussé de couleurs «À Mende chez Abraham Fontanel » Archives départementales de Clermont-Ferrand

À partir de janvier I766, cette image copiée, recopiée, est distribuée en même temps que la complainte pour Gabrielle Pélissier, elle-même reproduite sur feuilles volantes. Les deux jeunes filles sont confondues, les deux histoires rapprochées. Le nom d'Agnès Mourgues est oublié, mais celui de Gabrielle Pélissier est répété à l'infini; l'enfant nue s'efface devant la communiante en robe rouge, mais c'est le viol meurtrier dont elle fut victime qui alimente et justifie la catéchèse de la complainte. D'autres copies de l'image sont reprises jusqu'à nos jours, tout d'abord dans des occasionnels ${ }^{\text {II }}$ au XIX ${ }^{\mathrm{e}}$ siècle puis dans la majorité des ouvrages consacrés à la Bête du Gévaudan, enfin sur des céramiques, des carreaux de faïence, de la vaisselle... Reprises, réemployées, oui, mais avec une seule préoccupation commune : gommer le sexe de la Bête et élargir la tache de sang (figures 4 et 5).

Io. Archives départementales de Clermont-Ferrand, inventaire "La Bête du Gévaudan ", section "Maintien de l'ordre. Louvèterie», I765, I C 1734 : dessin à la plume rehaussé de couleurs, au bas : "À Mende chez Abraham Fontanel», H. II2, L. I60.

II. L’occasionnel, ancêtre du "canard", est une petite plaquette imprimée, diffusée par colportage dès l'introduction de l'imprimerie en France à partir de I450. Occasionnels et canards furent détournés de leurs objectifs premiers pendant les guerres de religion et devinrent les outils de propagande les plus exploités par catholiques et protestants. 


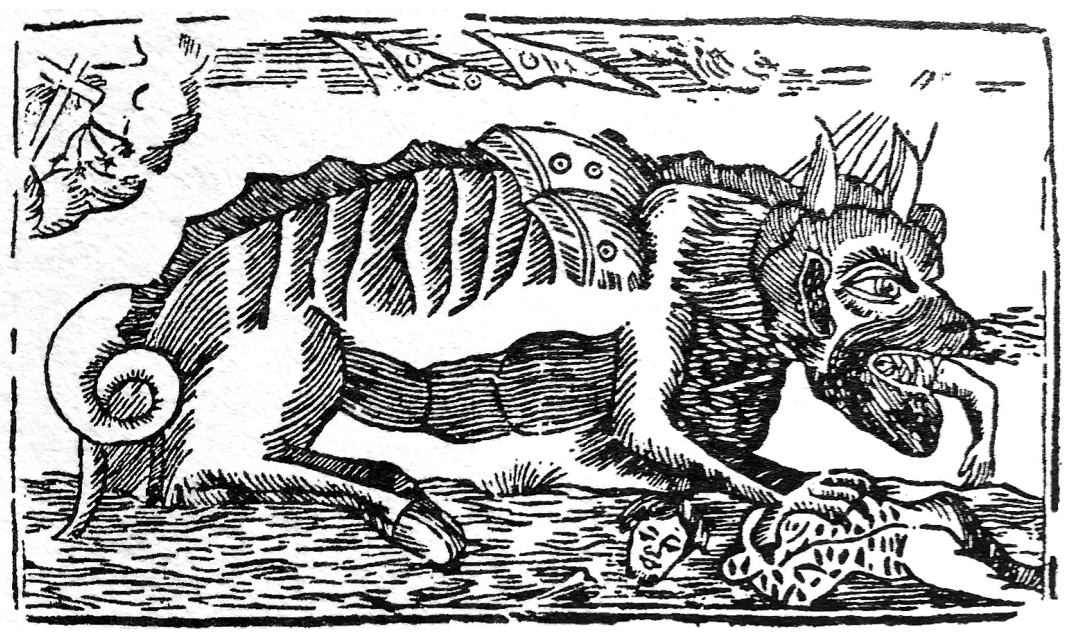

Figure 4 : Bois gravé. Clermont-Ferrand. XVIII ${ }^{\mathrm{e}}$ siècle Fonds privé

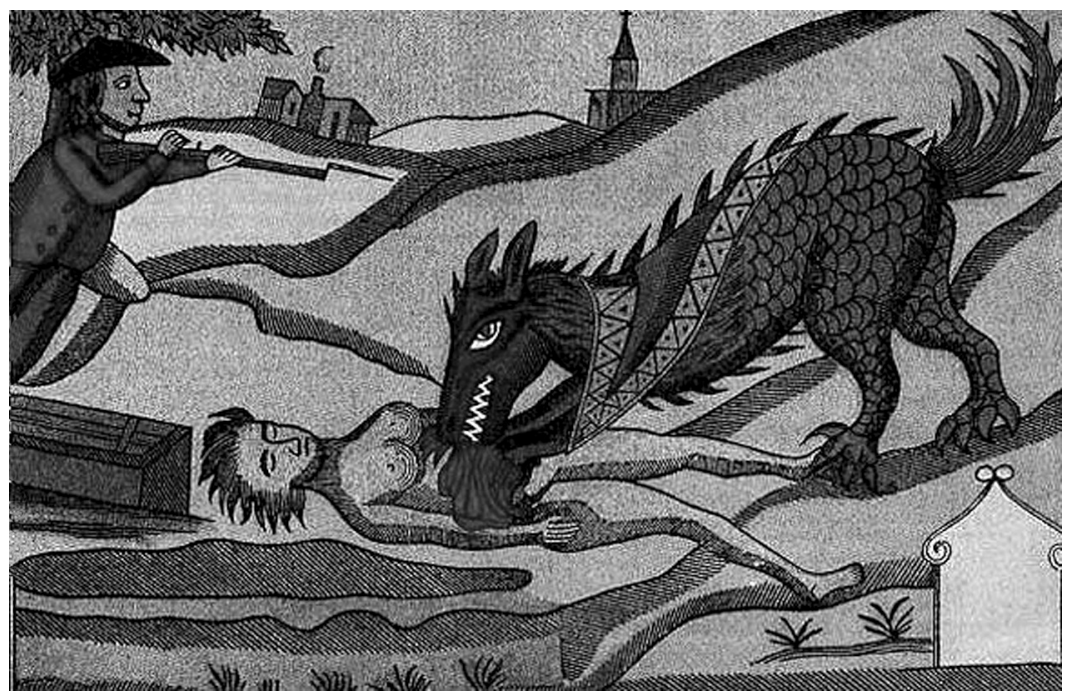

Figure 5 : François Fabre, La Bête du Gévaudan (gravure du XVIII ${ }^{\mathrm{e}}$ siècle) Paris, Librairie Floury, 1930, p. 135 Fonds privé

L'association de la complainte à l'image fait de ce dessin un des maillons essentiels de l'invention narrative qui a suivi les morts de Gabrielle Pélissier et d'Agnès Mourgues. La personnalité d'Abraham Fontanel y est pour beaucoup. Né à Mende en I740, ce marchand d'estampes a vingt-cinq ans 
en 1765 et il saisit l'opportunité de l'affaire Agnès Mourgues pour asseoir son pouvoir éditorial, d'autant plus que l'évêché de Mende lui sait gré de son engagement religieux : car il édite et diffuse les écrits de l'évêque de Mende, et ses publications participent de la lutte contre les Réformés des Cévennes. Quittant Mende pour Montpellier quelques années plus tard, c'est donc tout naturellement qu'il deviendra membre de la confrérie des Pénitents Bleus, célèbre pour son opposition aux protestants languedociens dès 1568 , puis sous Louis XIII, lors des saccages et des démolitions des églises. Les portes de l'aristocratie locale lui seront alors ouvertes, il saura conquérir une place de premier plan dans la vie culturelle montpelliéraine, au travers des remous politiques de la fin du XvIII ${ }^{\mathrm{e}}$ siècle, jusqu'à devenir le premier conservateur du premier musée de Montpellier, embryon de l'actuel musée Fabre.

Ce dessin naïf devient donc la matrice de nombre de gravures et on lui ajoute un signe iconique religieux : un crucifix ou une église, placés dans un coin, comme autant de marqueurs identitaires. Car la dévoration de ces bergères ne saurait être comprise sans une lecture catholique. Lorcières est le fief du curé Ollier, le principal rédacteur des méfaits de la Bête, la source principale aussi des informations collationnées par l'évêché de Mende. Quant à La Clauze, ce n'est pas un hameau ordinaire : ce village, associé à celui de Grèzes, est le fief de familles puissantes telles que La Rochefoucauld et La Tour-d'Auvergne, dominé par une tour de forme heptagonale, bel exemple d'architecture seigneuriale et belle affirmation aussi d'un pouvoir seigneurial sans partage. Plus important encore, le prieuré de Grèzes-La Clauze dépend de l'évêché de Mende : et cette dépendance est si importante pour l'évêché qu'il ne cèdera à l'abbaye de Préchac cette paroisse pourtant fort éloignée qu'en I929. Pourquoi? C'est que La Clauze n'est qu’à I9 $\mathrm{km}$ d'un lieu de pèlerinage indispensable pour les autorités religieuses aux prises avec l'affaire de la Bête : Notre-Dame-d'Estours. L'histoire du pèlerinage d'Estours s'est depuis longtemps ressentie, indifféremment, des malheurs ou de la prospérité du Gévaudan. Bravant les intempéries et l'hostilité naturelle du lieu, les pèlerins sont nombreux pour implorer la Vierge lors des famines, des épidémies, du pillage des bandes, et bien sûr, dès janvier 1765 , lorsque la Bête s'attaque aux bergers de la région de Saugues. On vient prier devant cette Vierge romane à l'allure majestueuse et hiératique. Son costume est analogue à celui qu'on trouve au XII ${ }^{\mathrm{e}}$ siècle dans les monastères de femmes en Auvergne. Elle tient sur ses genoux un enfant aux cheveux coupés ras et à la figure ingrate. Elle-même a en revanche un visage aux traits doux et réguliers. Ses cheveux sont cachés par un voile, relié à la robe par un galon circulaire, un genre de "pallium», décoré en 
son milieu par un gros bijou. Et l'enfant sur ses genoux est enveloppé d'une robe rouge.

On dit que de grandes grâces sont accordées à ceux qui viennent prier dans cette chapelle. C'est pourquoi le clergé du Gévaudan va donner rendezvous à la population en ces lieux sacrés : le jour de Pâques I766, un an jour pour jour après la mort de la «communiante» Gabrielle Pélissier, une procession monte sur le promontoire rocheux qui domine les gorges de la Seuge. La complainte en l'honneur de la jeune "communiante» y est distribuée. Puis, c'est le dimanche 7 juin i766, lors du dimanche de Pentecôte, qu'y est organisé un second pèlerinage. Le dimanche I4 juin 1766 , un troisième pèlerinage a lieu, cette fois à Notre-Dame-de-Beaulieu, autre lieu de dévotion mariale, concurrentiel de Notre-Dame-d'Estours : en cette chapelle située au centre d'immenses pâturages, de champs de genêts et de gentianes, le chasseur Jean Chastel, accompagné de ses fils, assiste à la messe. Il fait bénir trois balles de plomb fondu réalisées à partir de médailles représentant la Vierge Marie. Le I9 juin, le marquis d'Apchier décide d'organiser une ultime chasse. Et c'est à Nozeyrolles, près d'Auvers, non loin de NotreDame-d'Estours, qu'alors, enfin, Jean Chastel tue la Bête.

\section{Une version heureuse des histoires de Gabrielle et d'Agnès}

Il existe une version heureuse de l'histoire de Gabrielle Pélissier. Sous le titre exact La Petite Fille épargnée par les louveteaux, il s'agit d'un court récit en vers latins, composé dans le premier quart du $\mathrm{XI}^{\mathrm{e}}$ siècle par Egbert de Liège :

Ce que je rapporte, les paysans savent le dire avec moi,

Et il faut moins s'en étonner que le croire fermement vrai.

Quelqu'un tint une petite fille sur les fonts baptismaux

Et lui donna une robe tissée de laine rouge.

Ce baptême eut lieu à la Pentecôte.

Au lever du soleil, l'enfant, âgée de cinq ans,

Marche et vagabonde, sans se soucier d'elle-même et du danger.

Un loup s'en saisit, gagna la forêt sauvage et profonde,

L'apporta comme gibier à ses petits et la leur laissa à manger.

Ils se précipitèrent sur elle, mais, ne parvenant pas à la mettre en pièces,

Se mirent à lui caresser la tête, loin de toute sauvagerie.

"Je vous défends, souris, dit la jeune enfant, de déchirer cette robe

Que m’a donnée parrain à mon baptême!"

Dieu, qui est leur auteur, apaise les esprits sauvages ${ }^{12}$.

I2. Texte traduit et commenté par J. Berlioz, dans J. Berlioz, C. Bremond, C. Velay-Vallantin, Les Formes médiévales du conte merveilleux, Paris, Stock Moyen Âge, 1989, p. I33-I39. 
Nombre de folkloristes, parmi lesquels Paul Delarue, n'ont reconnu à cette histoire aucun lien génétique avec Le Petit Chaperon rouge, dont Perrault nous offrirait la plus ancienne version qui nous soit connue ${ }^{\mathrm{r} 3}$. Et d'ailleurs, il est incontestable que plusieurs éléments propres au conte de Perrault sont absents du récit d'Egbert de Liège : l'envoi de la petite fille chez sa grand-mère; les chemins différents pris par l'héroïne et le loup; la scène chez la grand-mère; la mort de l'enfant. Les deux récits présentent pourtant en commun l'épisode crucial du conte, la tentative de dévoration par un loup d'une fillette vêtue de rouge. Il est vrai que "le merveilleux dans le conte médiéval du Petit Chaperon rouge (d'Egbert de Liège) est encore très lié au surnaturel de la légende chrétienne ${ }^{\mathrm{I} 4}$ ». Plusieurs éléments inscrivent en effet ce récit dans une perspective strictement religieuse. Le baptême, tout d'abord. L'on sait que le baptême des enfants se développe à l'époque carolingienne et que les parrain et marraine deviennent des personnages importants pour l'Église qui tient à faire pénétrer le plus profondément possible une connaissance religieuse de base. Le cadeau de baptême est d'usage ancien et intervient moins à cette époque sous la forme d'une somme d'argent que par le don d'un animal, d'un bijou ou, comme c'est ici le cas, d'un joli vêtement. Quant à la Pentecôte, c'est avec Pâques le jour habituel dévolu à cette cérémonie. Enfin l'auteur insiste à présenter l'histoire comme s'étant réellement passée; il ne cite pas les paysans comme sa source, mais il prend leurs dires à témoin pour corroborer le sien. Pour lui, ce récit ne doit pas évoquer une fable, mais la relation d'un fait réel, éclatant témoignage de la puissance divine.

Prenant vigoureusement le contrepied de Paul Delarue pour qui la couleur rouge du chaperon est accessoire et ne saurait justifier que l'on établisse une filiation avec le conte de Perrault ${ }^{15}$, Jacques Berlioz, à la suite de Michel Pastoureau, a démontré que la mention de la couleur rouge ne saurait être due au hasard ${ }^{16}$. Le rouge est la couleur par excellence; consi-

I3. P. Delarue, «Les contes de Perrault et la tradition populaire», dans Bulletin folklorique d'Îlede-France, Paris, I951.

I4. H.-R. Jauss, Untersuchungen zur mittelalterliche Tierdichtung, Tübingen, I959, p. 67.

I5. J. Berlioz, "Un Petit Chaperon rouge médiéval? "La petite fille épargnée par les loups" dans la Fecunda Ratis d'Egbert de Liège (début du XI ${ }^{\mathrm{e}}$ siècle )", Marvels and Tales, Special Issue on Charles Perrault, vol. 5, nº 2, Wayne State University Press, déc. 1991, p. 246-263.

I6. M. Pastoureau, "Ceci est mon sang. Le christianisme médiéval et la couleur rouge», dans D. Alexandre-Bidon (dir.), Le Pressoir mystique (actes du colloque de Recloses, mai 1989), Paris, Cerf, I990, p. 43-46. Au XIII ${ }^{\mathrm{e}}$ siècle, le liturgiste Durand de Mende témoigne d'un vêtement de baptême porteur d'une frange rouge qui, cousue en dessus, marque la passion du Christ, "par laquelle le sacrement de baptême est consommé». Rouge et blanc sont indissociablement liés autour du baptême. Cité par J. Berlioz, dans Marvels and Tales, ouvr. cité, I99I, p. 262. 
déré comme une couleur vive et gaie, il caractérise la petite enfance. Le récit, attirant l'attention sur le vêtement de couleur — la tunique, lange de baptême —, souligne qu'il fait écart, lui attribuant un rôle signalétique évident. Le vêtement rouge, donc teint - la robe est, précise Egbert de Liège, tissée de laine rouge (rubicundo uellere textam) — s'oppose au vêtement blanc, non teint : si la chimie tinctoriale du Moyen Âge réussit ses meilleures performances dans la gamme des tons rouges, il reste que c'est une couleur qui coûte cher. Les teinturiers parviennent à faire pénétrer profondément la matière colorante, la garance ou le kermès, dans les fibres du tissu. De ce fait, sur un vêtement, même paysan, un ton rouge prend rarement cet aspect délavé et grisé qu’ont en général les autres couleurs. Comment étaient habillés les enfants en ce Haut Moyen Âge? Il est difficile de le dire; en revanche, à la fin de l'époque médiévale, si le blanc était privilégié pour tout vêtement interne, le rouge l'était pour les pièces supérieures, bandelettes, maillot de laine et robe. De plus, la mention de la couleur de la robe est là pour dénoter toute la qualité du don du parrain. Rouges sont les châles et les tuniques de baptême, rouges sont les robes de communion, parfois agrémentées de liserés blancs. Le rouge de la robe de la fillette sauvée par Dieu exprime la puissance divine face aux loups, créatures infernales. Le rouge sang pris positivement est en effet un rouge rédempteur et sanctificateur, qui purifie et donne la vie, c'est celui du Sauveur. Ce rouge christologique est un rouge dense, vif et dynamique, il est épais, il jaillit, il procure joie et santé. Le latin médical l'exprime par le terme ruber, parfois rubeus : dans l'iconographie, le Christ petit enfant est fréquemment représenté vêtu de rouge, comme dans le Sacramentaire de Limoges ou encore, sur les sculptures romanes auvergnates telles que celle de Notre-Dame-d'Estours. La robe rouge confère à la nouvelle baptisée vigueur et énergie face à la mort. À l'innocence de l'enfant, s'ajoute la force du Christ face au mal.

Certes, la couleur commune à la robe et au chaperon des deux fillettes ne suffit pas à fonder une filiation génétique, d'Egbert de Liège à Perrault, de Perrault au récit de la mort de Gabrielle Pélissier. Il est cependant établi qu'en ce milieu du XvıII ${ }^{\mathrm{e}}$ siècle, en Gévaudan, les usages vestimentaires n'avaient guère évolué depuis le Moyen Âge, en particulier dans le monde paysan. Ce récit du XI ${ }^{\mathrm{e}}$ siècle appartient bien au domaine du conte : la petite fille possède un don, en l'occurrence un vêtement de baptême rouge; avant de pouvoir en définir la destination, elle en connaît la fonction : la robe est un instrument de salut contre les loups. Mais pour rendre compte de la validité de la problématique contextuelle qui régit ce travail, il me faut moins m'attacher à une archéologie des textes qui aurait l'effet de 
reconstituer l'histoire de chaque écrit, qu'au problème de la réception : la perception des contes au sein d'une culture cléricale se modifie dans le temps. Ainsi, l'intérêt de ce texte du XI ${ }^{\mathrm{e}}$ siècle ne réside pas tant dans son antériorité hypothétique par rapport au conte de Perrault et au récit de la mort de Gabrielle Pélissier. En fait, la curiosité qu'il suscite vient de ce que, de toute évidence, en 1765 , quelqu'un — un ecclésiastique? un éditeur? connaissait l'histoire d'Egbert de Liège, se l'est appropriée, et l'a diffusée en la reconstruisant pour mieux masquer ce qui apparait très rapidement comme un crime, le meurtre d'une jeune fille, gardienne du troupeau familial. Ainsi, les auteurs anonymes des lettres et de la complainte de 1765 ont décidé de ne pas abandonner l'œuvre de l'écolâtre de Liège aux dérives du temps et de la réception : les voici qui préfèrent forger un nouvel exemplum, destiné à une tout autre compréhension, autant prosélyte cependant que l'original du $\mathrm{XI}^{\mathrm{e}}$ siècle. La question n'est pas tant de savoir quel était l'usage de ce récit au début du $\mathrm{XI}^{\mathrm{e}}$ siècle. Une fois qu'on a dit que ce récit, emprunté aux paysans, renvoie au genre des contes d'avertissement, destinés aux enfants qu'ils mettent en garde contre les dangers extérieurs, on a fait un travail classique d'historien positiviste. Et une fois qu'on a ajouté que la petite fille, loin de trouver la mort de par son imprudence, est sauvée par la divine Providence grâce à sa robe rouge, on a fait œuvre d'historien des mentalités. Mais pour restituer la violence faite au texte, il est nécessaire de travailler sur le contexte historique qui a refaçonné un conte en une mise en scène destinée à dissimuler et à justifier un meurtre.

En Gévaudan, Gabrielle Pélissier se voit investie des mêmes pouvoirs que la petite fille d'Egbert de Liège. Communiante — bien tardive au demeurant —, sommée de dire ses prières par un père qui la « réconforte» avant de la laisser seule avec le troupeau, Gabrielle est vêtue de sa robe de communiante, dont la couleur est rouge, comme celle d'une robe de baptême : robe de communiante, châle et tunique de baptême, autant de vêtements magiques qui sont censés paralyser le loup dévorant. Mais son aventure finit mal. C'est que les narrateurs chargés de reconstruire son histoire, peu de temps après le meurtre, ont bien l'intention de démontrer qu'elle est d'emblée disqualifiée aux yeux de Dieu. Gabrielle a beau garder ses vaches en un lieu où la sauvegarde de la Vierge lui est acquise — «La-Champ-de-la-Dame» —, elle ne peut rien contre le châtiment dont est chargée la Bête ${ }^{17}$. Les lettres, la complainte, l'aquarelle sont toutes

17. «La-Champ-de-la-Dame» : le mot occitan «lachamp» désigne un grand pâturage, la «Dame» signifie la Vierge. 
porteuses de leçons données à entendre à la population du Gévaudan : elles vont à l'encontre du partage ambigu entre magie et puissance divine que le récit $\mathrm{du} \mathrm{XI}{ }^{\mathrm{e}}$ siècle énonce ingénument. Les témoignages contradictoires sur les circonstances de sa mort, associés aux descriptions effrayantes du corps décapité et démembré puis recomposé, attestent la circulation d'un récit oral, proche de celui du $\mathrm{XI}^{\mathrm{e}}$ siècle, ou encore plus vraisemblablement l'exploitation lettrée du récit d'Egbert de Liège. Ce n'est pas tant la question de la permanence narrative qui importe ici, mais plutôt l'usage dont le récit fait l'objet, noria de techniques démonstratives et persuasives aboutissant à une effrayante évidence : une robe consacrée, au XVIII ${ }^{\mathrm{e}}$ siècle, en un Gévaudan hérétique, ne peut plus secourir personne. Et que dire d'Agnès Mourgues? Petite bergère qui n'a que des prés communaux où garder ses vaches, en plein hiver - est-ce crédible? - , elle n'a que son courage pour se défendre contre ce qui est clairement relaté comme un viol suivi d'un martyre meurtrier. Le récit est d'un réalisme saisissant et, à l'inverse de celui de la mort de Gabrielle, il énonce des données connues du monde paysan : l'épisode des «bestiaux en déroute", plus vraisemblable, est l'exact contraire de celui des vaches prêtes à défendre la communiante. Mais surmontant son émotion, l'abbé Ollier abandonne cette écriture trop crue et saisit l'occasion de l'épilogue pour mieux se soumettre aux prescriptions pédagogiques de l'exemplum : la Bête a laissé Agnès telle qu' "elle était comme si elle venait de naître", dépourvue des sacrements de l'Église. De Gabrielle Pélissier à Agnès Mourgues, du mois d'avril au mois de décembre 1765 , s'égrènent à rebours les sacrements de l'initiation chrétienne, l'eucharistie de la Pâque, la confirmation, le baptême, jusqu'à cet ultime et désespérant retour aux sources : l'enterrement de la fillette, aussi démunie qu'un nouveau-né non baptisé.

\section{Le mandement de l'évêque de Mende}

Les relations, les récits, les complaintes, les images, ces narrations et ces représentations, bref, tout cet édifice n'est en fait redevable qu'à un seul texte, générique de tous les autres : le Mandement de Monseigneur l'Évêque de Mende, pour ordonner des prières publiques, paru à Mende chez la veuve de François Bergeron le 3I décembre 1764. Marguerite Paulet, épouse de François Bergeron, imprimeur attitré de l'évêché de Mende, du clergé et du collège, lui a succédé à sa mort en I755. François Bergeron, originaire du Puy-en-Velay, a travaillé depuis 1722 chez la veuve de son oncle Jacques Roy, déjà connu pour son attachement à l'évêché de Mende. L'implantation 
puis l'enracinement à Mende de cette famille réputée au Puy pour son catholicisme militant provoqueront le départ pour Montpellier de leur jeune rival, Abraham Fontanel, qui ne dispose pas de leurs privilèges. Voici quelques extraits du Mandement:

C'est parce que vous avez offensé Dieu que vous voyez aujourd'hui accomplir en vous à la lettre et dans presque toutes leurs circonstances les menaces que Dieu faisait autrefois par la bouche de Moïse contre les prévaricateurs de sa loi : "J'armerai contre eux, leur disait-il, les dents des bêtes farouches (Deutéronome, XXXII, 24). J'enverrai contre vous les bêtes sauvages qui vous dévoreront, vous et vos troupeaux, qui vous réduiront à un petit nombre et qui de vos chemins feront un désert. (Lévitique, XXVI, 20) : à cause que la crainte que vous aurez de ces bêtes vous empêchera de sortir pour vaquer à vos affaires. Ils m’ont oublié, dit-il encore, et moi je serai pour eux comme une lionne; je les attendrai comme un léopard sur le chemin de l'Assyrie; je viendrai à eux comme une ourse à qui on a ravi son petit; je leur ouvrirai les entrailles, et leur foie sera mis à découvert, je les dévorerai comme un lion et la bête farouche les déchirera. " Ces textes de la Sainte-Écriture que nous choisissons parmi bien d'autres suffisent pour convaincre que dans tous les temps Dieu a menacé de punir les péchés des hommes par des supplices semblables à celui dont vous éprouvez aujourd'hui toute la rigueur. Ne demandez donc plus d'où est venue la Bête féroce, qui fait tant de ravages parmi nous; ne vous mettez point en peine de savoir comment elle a pu pénétrer jusqu'à nous. C'est le Seigneur qui l'a tirée du trésor de sa colère; c'est le Seigneur irrité qui l'a lâchée contre vous; c'est le Seigneur qui dirige sa course rapide vers les lieux où elle doit exécuter les arrêts de mort que sa justice a prononcés. Tel est l'ordre immuable de cette justice éternelle, que l'homme ne puisse se révolter contre son Créateur, sans soulever contre lui toutes les créatures; sa révolte lui a fait perdre l'empire absolu qu'il lui avait donné sur tous les animaux et cette même révolte a donné une espèce de domination et de supériorité sur l'homme, puisque celui-ci est souvent livré à leur fureur en punition de ses péchés.

Pères et mères, qui avez la douleur de voir vos enfants égorgés par ce monstre que Dieu a armé contre leur vie, n'avez-vous pas lieu de craindre d'avoir mérité par vos dérèglements, que Dieu les frappe d'un fléau si terrible? Souffrez que nous vous demandions un compte de la manière dont vous les élevez; quelle négligence à les instruire des principes de la religion et des devoirs du christianisme, quel soin prenez-vous de leur éducation? Au lieu de leur apprendre de bonne heure et dès leurs plus tendres années à craindre Dieu et à s'abstenir de tout péché, [...] ne leur inspirez-vous pas des sentiments tout opposés, d'ambition, d'orgueil, de mépris pour les pauvres, de dureté pour les misérables? On vous voit bien moins occupés de leur salut que de leur fortune et de leur avancement, pour lequel tout vous paraît légitime, et ces passions naissantes que vous auriez dû arrêter et étouffer par des corrections salutaires, vous prenez soin au contraire de les nourrir et d'en faire éclore le germe; heureux encore si vous n'étiez pas les premiers à les pervertir et à les corrompre par la contagion de vos mauvais exemples! Après cela, faut-il être surpris que Dieu punisse l'amour déréglé que vous avez pour eux par tant de sujets d'afflictions et de douleur qu'il vous prépare dans la suite de votre vie? Quelle dissolution et quel dérèglement dans la jeunesse de nos jours! La malice et la corruption se manifestent dans les enfants avant qu'ils aient 
atteint l'âge qui peut les en faire soupçonner. Ce sexe dont le principal ornement fut toujours la pudeur et la modestie, semble n'en plus connaître aujourd'hui ; il cherche à se donner en spectacle, en étalant toute sa mondanité et il se fait gloire de ce qui devrait le faire rougir. On le voit s'occuper à tendre des pièges à l'innocence, à usurper un encens sacrilège et à s'attirer jusques dans nos temples des adorations qui ne sont dues qu'à la Divinité. Une chair idolâtre et criminelle qui sert d'instrument au démon pour séduire et perdre les âmes, ne mérite-t-elle pas d'être livrée aux dents meurtrières des Bêtes féroces qui la déchirent et la mettent en pièces? Ce n'est pas que nous regardions comme coupables toutes les personnes qui ont eu le malheur de périr de la sorte; Dieu peut avoir permis ces tristes événements pour des raisons qui regardent leur salut et leur bonheur éternel; mais cela n'empêche pas que Dieu leur a fait subir la peine due aux péchés de leurs parents : "Je suis, nous dit-il, le Dieu fort et jaloux qui venge l'iniquité des pères sur les enfants jusqu'à la troisième et quatrième génération.» (Exode, XX, 5.)

Plusieurs remarques découlent de la lecture de ce texte : tout d'abord, la précocité métaphorique de la qualification de la Bête. L'évêque de Mende est sans conteste un des premiers à avoir suscité l'émergence de la légende; sans doute les témoignages des abbés et des chasseurs l'ont-ils conforté dans son interprétation des dévorations; mais il reste que le choix des images et des sources scripturaires lui revient de plein droit et que c'est ce choix qui a inspiré éditeurs, conteurs, historiens et romanciers dès ce moment jusqu'à nos jours. L'artisan de la légende, c'est Choiseul-Beaupré. Il est le devancier, involontaire peut-être, de ce qu'il dénonce plus loin comme "ces contes fabuleux dont le peuple grossier aime à se repaître».

Si une longue tradition fictive est redevable au Mandement de l'évêque de Mende, c'est aussi à cause de la construction narrative de ce texte. Le Mandement est élaboré comme une épître, à l'imitation de celles de saint Paul. Cette influence se reflète dans le style comme dans la rhétorique : par exemple, Choiseul-Beaupré doit à la discussion d'école, la «diatribe» cynico-stoïcienne, son mode d'argumentation serré par courtes questions et réponses, ou ses développements par accumulation rhétorique. En fait, ce Mandement est un écrit occasionnel, une réponse actualisée à une situation concrète et non un traité de théologie : le modèle des Épitres de saint Paul est si visible que le curé de village, chargé de lire en chaire le texte épiscopal, ne s'y trompera pas et attribuera à Choiseul-Beaupré l'autorité d'un prédicateur.

Mais la prédication de l'évêque de Mende est loin du «kérygme» apostolique, cette proclamation du Christ crucifié et ressuscité. La conversion des païens gévaudanais, l'enseignement eschatologique, les exhortations pratiques, doivent beaucoup moins aux Évangiles qu'aux traditions de l'apocalyptique juive et du christianisme primitif, tel le discours eschatologique 
des Synoptiques, de Matthieu par exemple. L'inspiration de ce texte est nourrie de versets ou plutôt de morceaux de versets bibliques, souvent ajoutés bout à bout, l'un appelant l'autre par une démarche analogique. Examinons de plus près les citations bibliques choisies par l'évêque de Mende; leur original latin est précisé en note dans la première édition du Mandement; destinée de toute évidence en priorité aux ecclésiastiques, elles sont toutes extraites du Pentateuque : le Deutéronome, le Lévitique, et l'Exode. Et elles font toutes référence à la même situation et à la même histoire religieuse : Moïse, qui a reçu la révélation du nom incommunicable de Yahvé au Sinaï, y ramène les Israélites libérés de la servitude en Égypte; dans une théophanie impressionnante, Dieu fait alliance avec le peuple et lui dicte ses lois; mais à peine conclu, le pacte est rompu par l'adoration du veau d'or; Dieu pardonne et renouvelle l'Alliance; une série d'ordonnances règle alors le culte au désert. Cette histoire est indéfiniment répétée dans les cinq premiers livres de la Bible. Le peuple retombe incessamment dans ses errements, adoration de dieux païens et respect de pratiques religieuses antérieures ou voisines comme celles de l'Assyrie. Le Pentateuque est le livre de cette noria de retours au péché qui cause le courroux de Dieu et son châtiment : la dévoration des infidèles par les bêtes féroces.

S'il est donc une histoire retenue par l'évêque de Mende, c'est bien celle-là : s'il est un péché intolérable, c'est bien le refus par Israël de l'Alliance offerte par Dieu. La sanction est constamment associée aux rappels des conditions de la fidélité, réglées par Dieu lui-même. Au peuple qu'il s'est choisi, Dieu donne sa loi. Celle-ci l'instruit de ses devoirs, règle sa conduite conformément au vouloir divin et, en maintenant l'Alliance, prépare l'accomplissement des promesses. Les thèmes de la promesse, de l'élection, de l'alliance et de la loi sont les fils conducteurs du Pentateuque, et d'une manière générale, de tout l'Ancien Testament. Mais, dans la construction des livres, ils ne peuvent être compris dans leur totalité que s'ils sont identifiés comme autant de bontés du Dieu créateur et indéfiniment opposés aux trahisons de l'homme pécheur. Alors, répété à plaisir, le motif des bêtes féroces devient le symptôme de l'ampleur de l'infidélité.

Monseigneur Gabriel-Florent de Choiseul-Beaupré, évêque de Mende de 1723 à sa mort en 1767 , a rédigé ce texte lui-même; théologien érudit, il a déjà publié les nouveaux Statuts synodaux de 1738, une Lettre pastorale [...] pour justifier la doctrine des Conférences de son diocèse sur la grâce effcace par elle-même, la prédestination gratuite... chez la veuve de François Bergeron en 176I, et un Mandement au sujet du nouveau bréviaire qu'il donne à son diocèse, publié chez J.T. Hérissant en I763. Choiseul-Beaupré 
est aussi un évêque qui passe à l'acte : en 1763 , il déclasse Sévérien de la liste des évêques de Mende, soupçonnant une confusion avec Sévérien de Gabala, connu pour ses démêlés avec Jean Chrysostome et pour son indiscipline colérique. Il choisit alors pour Mende un saint patron plus conforme à ses vœux : saint Privat, invention hagiographique parfaitement réussie, dont le succès ne se dément pas jusqu'à nos jours. Il écrit donc son Mandement selon les règles coutumières des écrits apocalyptiques. Pour argumenter sur le thème de la Bête de l'Apocalypse, il fallait un érudit et un habile connaisseur des textes bibliques, en particulier de l'Ancien Testament. Mais il fallait aussi savoir que ces textes étaient lus dans les familles gévaudanaises avec autant d'intérêt que les Évangiles. Car seul l'évêque de Mende peut ainsi se saisir d'un fait divers pour condamner les hérésies passées des Gévaudanais, pour les rappeler à l'obéissance, pour évoquer le pardon hypothétique de leur plus grande faute : celle de leurs pères, les Camisards du début du siècle. Car rappelons-nous sa dernière citation biblique : "Je suis le Dieu fort et jaloux qui venge l'iniquité des pères sur les enfants jusqu’à la troisième et quatrième génération.» En I764, soit soixante ans après les troubles cévenols, ce sont donc bien les troisième et quatrième générations qui sont visées.

Voici un bien curieux prélat, dont les références bibliques proviennent exclusivement de l'Ancien Testament. Il va même jusqu'à reprendre à son compte certaines formules, et si la construction du Mandement est à l'aune des Épitres de saint Paul, le rappel du pardon christique est absent de toute son argumentation. Ne suspectons pas pour autant Choiseul-Beaupré de sympathies huguenotes! Il semble plutôt que l'évêque ait voulu attaquer les protestants sur leur propre terrain : les références des prédications des «prophètes du désert» sont abondamment choisies parmi l'Ancien Testament. Les commentaires de L'Apocalypse ont été retrouvés à plusieurs reprises dans les bagages des "fanatiques", appliqués bien entendu aux événements présents; pour les Camisards, c'est l'Église catholique qui est la "Bête» ou «la grande Babylone», et ce sont les Cévenols les élus de l'Agneau. Le discours prophétique des Camisards s'est nourri de toutes les allusions de l'Ancien Testament sur la lutte d'Israël contre ses ennemis, les Syriens, les Philistins, les Assyriens ou les Madianites. En réalité, l'assimilation au peuple élu a été absolue pour les insurgés. Pour eux, les Cévennes ont été le nouvel Israël. Philippe Joutard a montré qu'il y avait continuité entre la période des "prophètes» et les autres phases de la résistance protestante : même sentiment de l'homme pécheur qui s'est éloigné de Dieu — la prédication camisarde rejoint là un courant réformé calviniste beaucoup plus 
ancien —, même appel à la repentance et à la sortie de Babylone, même certitude du salut pour le petit peuple qui n’a pas cédér ${ }^{18}$. Nouvel Israël, le peuple camisard s'est confié totalement au prophétisme qui était pour lui la preuve de la sollicitude de Dieu à son égard et qui devait donc structurer entièrement son organisation. Le discours prophétique cévenol, incitation à la résistance armée, n'en était que plus dangereux.

Le Mandement de l'évêque de Mende reprend donc en toute connaissance de cause les mêmes sources que celles des Camisards. Il exploite la même exégèse scripturaire. Il pousse l'habileté jusqu'à utiliser le cliché par lequel on a identifié les Camisards : des "bêtes féroces", formule mise au goût du jour par Voltaire et les cercles parisiens qui osent renvoyer dos à dos Camisards et catholiques. Ceci est intolérable pour l'évêque de Mende et un an après les derniers écrits de Voltaire, l'actualité lui donne l'occasion de répondre, presque mot pour mot, selon une rhétorique habile, celle de la réversibilité de la filiation narrative : la Bête du Gévaudan est bien effectivement celle de l'Apocalypse mais c'est celle que les Cévenols ont réveillée par la plus grave des trahisons, l'apostasie.

La diabolisation de la Bête fait rapidement son chemin. Les figures et métaphores exploitées pour la décrire en rendent d'ailleurs parfaitement compte : par exemple, l'abbé Ollier de Lorcières, dans sa relation de janvier I766, fait appel aux habituels attributs du diable pour la dépeindre : "L'animal féroce et vorace a un corps allongé, et par conséquent deux fois plus long qu'un loup ordinaire et beaucoup plus haut [...] avec des dents si tranchantes qu'elles séparent en peu de temps la tête d'une personne, en un mot coupantes comme des rasoirs [...], le poitrail beaucoup plus large quasi comme celui d'un cheval $[. .$.$] avec une raie noire tout au long$ du dos. » Michel Pastoureau a montré la disqualification de cette rayure :

Les animaux (dans le Roman de Renart) au pelage rayé ou tacheté se rangent du côté des animaux à pelage roux et constituent le clan des menteurs, des voleurs, des lubriques ou des cupides. Pour la société animale comme pour celle des hommes, être roux, rayé ou tacheté est à peu près équivalent. Cette méfiance, cette peur même des animaux tachetés ou rayés a laissé des traces de longue durée dans l'imaginaire occidental. Au XVIII ${ }^{\mathrm{e}}$ siècle, la fameuse bête du Gévaudan, qui, en 1764-1767, sema la terreur aux confins de l'Auvergne et du Vivarais, est décrite par tous ceux qui l'ont vue, ou cru voir, comme un loup gigantesque ayant le dos zébré de larges rayures. Créature diabolique, cette "Bête» du Gévaudan ne pouvait pas ne pas être rayée. À sa suite, fut également rayée chacune

18. P. Joutard, La Légende des Camisards. Une sensibilité au présent, Paris, Gallimard, I977, p. $44-48$. 
des autres «Bêtes du Gévaudan» qui, pendant plusieurs décennies, parfois jusqu'en plein milieu du XIX ${ }^{\mathrm{e}}$ siècle, troublèrent les esprits et les campagnes de France ${ }^{19}$.

C'est ainsi que, rayée comme la décrit l'abbé Ollier, ou tachetée comme le léopard auquel l'associe l'évêque de Mende, la Bête du Gévaudan prend place dans le bestiaire de Satan.

Mais pourquoi donc Choiseul-Beaupré accuserait-il la population catholique, plutôt dévote, de cette région nord du Gévaudan, qui correspond au département actuel de la Haute-Loire et du nord de la Lozère, d'éprouver des sympathies envers les Camisards cévenols avec qui les contacts sont rares? Il est probable que cet évêque, né à Dinant, évêque de Saint-Papoul jusqu'en 1923, ignore les frontières géographiques et culturelles qui isolent et enclavent les Cévennes au cœur du Gévaudan et qu'il exagère le pouvoir de persuasion des Camisards. Son inquiétude est cependant justifiée en ce qui concerne la ville de Mende et certaines régions méridionales de la Margeride plus ouvertes et sensibles aux Réformés. Mais il y a plus : le Mandement vise prioritairement les inconduites féminines. Qu'en est-il exactement?

\section{Viols en Gévaudan}

"Quelle dissolution et quel dérèglement dans la jeunesse de nos jours!», s'exclame l'évêque de Mende. Et le voilà qui s'emploie à poursuivre les femmes de ses foudres pour cause d'impudicité, de mondanité, de provocation sexuelle, de séduction. Elles seraient plus fréquemment sélectionnées par la Bête pour être ses victimes : pour Choiseul-Beaupré, elles sont donc des coupables de choix; parmi elles, Gabrielle Pélissier, dont le meurtre à venir trouve ses légitimations, n'en doutons plus, dans le texte épiscopal.

Mais tout d'abord, que nous disent les chiffres à propos de cette abondance de meurtres féminins? Environ $66 \%$ des victimes sont des femmes en $1764,58 \%$ en $1765,42 \%$ en 1766 , et $68 \%$ en $1767:$ la majorité est significative certes, mais de quoi? En tout cas, elle n'est pas aussi écrasante que la légende le laisse croire.

Élisabeth Claverie et Pierre Lamaison ${ }^{20}$ ont mis à jour un certain nombre de fonctionnements familiaux qui permettent de rappeler quelques faits : d'une part, dans une région où les bergères tiennent un rôle important dans l'économie domestique, il ne faut pas être surpris de les compter en majorité

19. M. Pastoureau, L'Etoffe du diable. Une histoire des rayures et des tissus rayés, Paris, Seuil, «La Librairie du Xxe siècle", I99I, p. 45-46.

20. É. Claverie et P. Lamaison, L'Impossible mariage. Violence et parenté en Gévaudan, XVII ${ }^{e}, X V I I I^{e}$ et $X I X^{e}$ siècles, Paris, Hachette, I982, p. 59 et suiv. 
parmi les victimes. Quelle fonction les femmes ont-elles dans la désignation de l'héritage? Élisabeth Claverie et Pierre Lamaison démontrent que dès la fin du XVII ${ }^{\mathrm{e}}$ siècle, les enfants qui n'héritent pas de l'ousta ${ }^{21}$ reçoivent une dot, "en guise de légitime", leur permettant de se marier : quand ils sont dotés, les garçons le sont moins que leurs sœurs; outre quelques meubles, divers instruments ménagers et quelques robes, il arrive - une fois sur cinq - que les filles reçoivent des têtes de bétail, vaches et brebis, plus rarement un bœuf, et très exceptionnellement un cheval. L'écart séparant la dot des garçons de celle de leurs sœurs montre bien que ces donations faites «en guise de légitime», et qui devraient être identiques pour tous les enfants d'une famille, demeurent en fait à la discrétion des parents.

Ces jeunes filles aisées, dotées de troupeaux, se retrouvent donc en compagnie d'autres bergères moins dotées, dans des prés éloignés des villages, isolés de ceux-ci par des bois. Depuis le XvII ${ }^{\mathrm{e}}$ siècle, la pratique du gardiennage collectif des troupeaux est homogène en Gévaudan; c'est lors de ces gardes qu'interviennent les viols. Dès leur plus jeune âge, ces enfants ont la charge du troupeau familial, ou bien elles sont louées à l'extérieur à un maître pour exécuter ce travail. Tôt le matin, au cours de la période d'estive — de mai à octobre —, elles partent avec les bêtes jusqu'à la nuit tombante. Les jeunes bergères, quelle que soit leur condition sociale, sont seules au pré. L'expérience que connaissent ces enfants, et que l'on peut comparer à une initiation, est celle de la solitude, de la peur, et aussi celle de la propriété, des limites, des bornages, de l'élevage enfin et du soin du bétail. La tâche consiste, par tous les temps, à veiller à ce que les bêtes ne s'égarent pas, ni ne sortent des limites imparties pour dévorer l'herbe ou les cultures avoisinantes; la moindre négligence est sévèrement punie. Pour tromper l'ennui, les filles tentent de se retrouver ensemble lorsqu'elles gardent des troupeaux contigus; et quand elles sont seules, elles filent la laine, font de la dentelle, ou s'essaient à la lecture dans leur livre de prière. Cette peur ressentie dans l'enfance semble marquer le Haut Gévaudan, et au hasard des procès, plus d'un adulte avoue ne pas oser traverser seul le bois, ou s'écarter des villages. La peur sourd des villages, des bois environnants et accompagne tous les récits paysans.

Alors, les jeunes bergères se livrent entre elles à des jeux : "Quelquefois, en gardant les bêtes, les enfants se dénudent en badinant. " Ce "badinage " n'est sans doute pas étranger à la réputation qu'ont les filles qui se louent comme bergères. Mais ces jeux sont bien différents de la violence qui les menace. Ces enfants sont donc souvent seules au loin. Un berger voisin,

2I. Ousta : mot occitan signifiant ferme familiale et par extension maison. 
cadet célibataire le plus souvent, surgit par surprise devant l'une d'entre elles, la viole en la menaçant de représailles si elle en parle. La bergère rentre chez elle terrorisée, et ne dit rien à ses maîtres ou à ses parents par crainte d'être battue, mais se précipite en confession. Sa mère ou sa maîtresse finit par s'apercevoir de ce qui s'est passé, en voyant du sang sur sa chemise et, suivant les cas, se tait ou engage un arrangement.

Choiseul-Beaupré se situe donc dans cette gamme de comportements de dénégation de la violence : en accusant les filles de provocation sexuelle, il leur reproche de s'affirmer absentes de leur responsabilité; l'aveu déclencherait au contraire une série de réactions contrôlées, rejet, puis pardon, et le groupe familial, communautaire et religieux, pourrait alors exprimer toutes les variations émotionnelles de sa morale. En revanche, le déni de responsabilité est interprété comme un défi qu'il faut réprimer. Or, l'évêque de Mende se heurte à forte partie : car les bergères violées sont choisies parmi le groupe des filles célibataires, toutes origines sociales confondues. Refusant toutes ensemble l'aveu de culpabilité, entraînant sur le terrain éthique des groupes familiaux avides de dédommagement financier, elles désignent et exploitent les faiblesses et les brèches de l'idéologie sociale et religieuse. De Gabrielle Pélissier à Agnès Mourgues, de la riche jeune fille, chargée du troupeau familial, à la bergère sans doute louée, qui mène les vaches au pré communal au cœur de l'hiver enneigé de Lorcières, de celle qui dit ses prières à celle qui se défend..., ces deux histoires apparemment dissemblables présentent pourtant les caractéristiques communes aux agressions sexuelles. Alors, heureusement pour Choiseul-Beaupré et pour le bénéfice de son autorité, surgit la Bête : la voici qui permettra de réguler les récompenses et les châtiments prônés par les instances officielles.

\section{L'image fondatrice d'un conte mystique}

Les relations du curé de Lorcières, l'abbé Ollier, sont les principales sources des occasionnels parisiens : sa croyance en la version de la Bête extraordinaire, délibérément transmise par écrit dans un but de diffusion, et son intelligence des effets politiques du fait divers ont contribué à cette influence à première vue insolite d'un curé de campagne sur un éditeur parisien. En effet, il est le premier à inventer la tradition des préférences sexuelles de la Bête : "Ainsi un loup n'a pas cet instinct de couper si bien les têtes des personnes surtout celles du sexe de préférence.» Il ressort de ses récits une impression d'authenticité ou en tout cas de sincérité indiscutable. Avec son témoignage, la légende acquiert une force nouvelle. Elle n'est plus 
simplement le reflet d'une tradition orale exprimant l'imaginaire paysan, mais le résultat d'une analyse écrite et savante. Personne ne s'y trompe; en tout cas, pas les imprimeurs qui se saisissent avec bonheur des détails incongrus que l'abbé accumule : par exemple la longueur de l'empreinte des pieds du monstre, seize centimètres, est ajoutée en marge de leurs éditions de colportage sous la forme d'un trait vertical, comme si l'unité de mesure de la patte de la Bête devenait celle du livret. Le témoignage « historique» livre alors sa fonction cachée : incarnant le monstre et ses propres métamorphoses diaboliques, le livret participe d'usages magiques et de ce fait, produit de nouvelles performances narratives, pour d'autres formes et d'autres publics.

Très tôt, les éditeurs parisiens s'emparent de l'affaire, sous forme de feuilles volantes tout d'abord, d'occasionnels par la suite. Le loup est décrit comme une bête surnaturelle et maléfique, ce qui explique sa soumission à la mort devant un chasseur mystique, le paysan Chastel. Mais c'est l'image qui met en évidence la stratégie didactique des éditeurs. En I764, F.-G. Deschamps, libraire rue Saint-Jacques à Paris, met en vente un occasionnel : Figure / de la bête / farouche / et extraordinaire, qui dévore les filles / dans la province de Gévaudan. Le bois gravé pour Deschamps représente la Bête qui tient entre ses pattes un(e) enfant, à peine plus gros(se) qu'une poupée (figure 6). Le libraire va plus loin en 1769 : dans une nouvelle édition de son occasionnel, il offre à son public parisien une simple représentation de la Bête dépourvue de sa victime, tandis qu'il destine au public languedocien l'image complète, enfant comprise. Cette édition continue à être diffusée dans les provinces françaises durant plusieurs années. Le projet de Deschamps apparaît encore plus clairement lorsqu'il apprend qu'en août I766, à Sarlat, en Périgord, des massacres semblables à ceux du Gévaudan sont perpétrés : le libraire de la rue Saint-Jacques diffuse alors un occasionnel relatant les circonstances de ces dévorations, qu'il accompagne, par commodité peut-être, de l'image recyclée de la Bête du Gévaudan; mais comme à Paris, il manque à cette image-là la représentation de sa victime. Deschamps s'en explique : "Cet animal faisait le contraste de la Bête du Gévaudan, car celle-ci n’en voulait qu'aux hommes, au lieu que celle du Gévaudan attaquait les femmes de préférence.» Cela revient à dire clairement que la dévoration d'un garçon est irreprésentable. Et pour cause : il n'existe pas de matrice antérieure. En I900, Auguste Vimar empruntera à l'image de l'occasionnel les quelques traits du cul-de-lampe qui met un point final au conte mystique d'une petite fille «inutile au monde», le Petit Chaperon rouge 22 (figure 7).

22. Voir l'analyse du traitement de l'exclusion dans la longue durée par B. Lepetit, «Le travail de l'histoire (note critique)", dans Annales, Histoire, Sciences Sociales, $5 \mathrm{I}^{\mathrm{e}}$ année, n ${ }^{\circ}$, 1996, p. 525- 


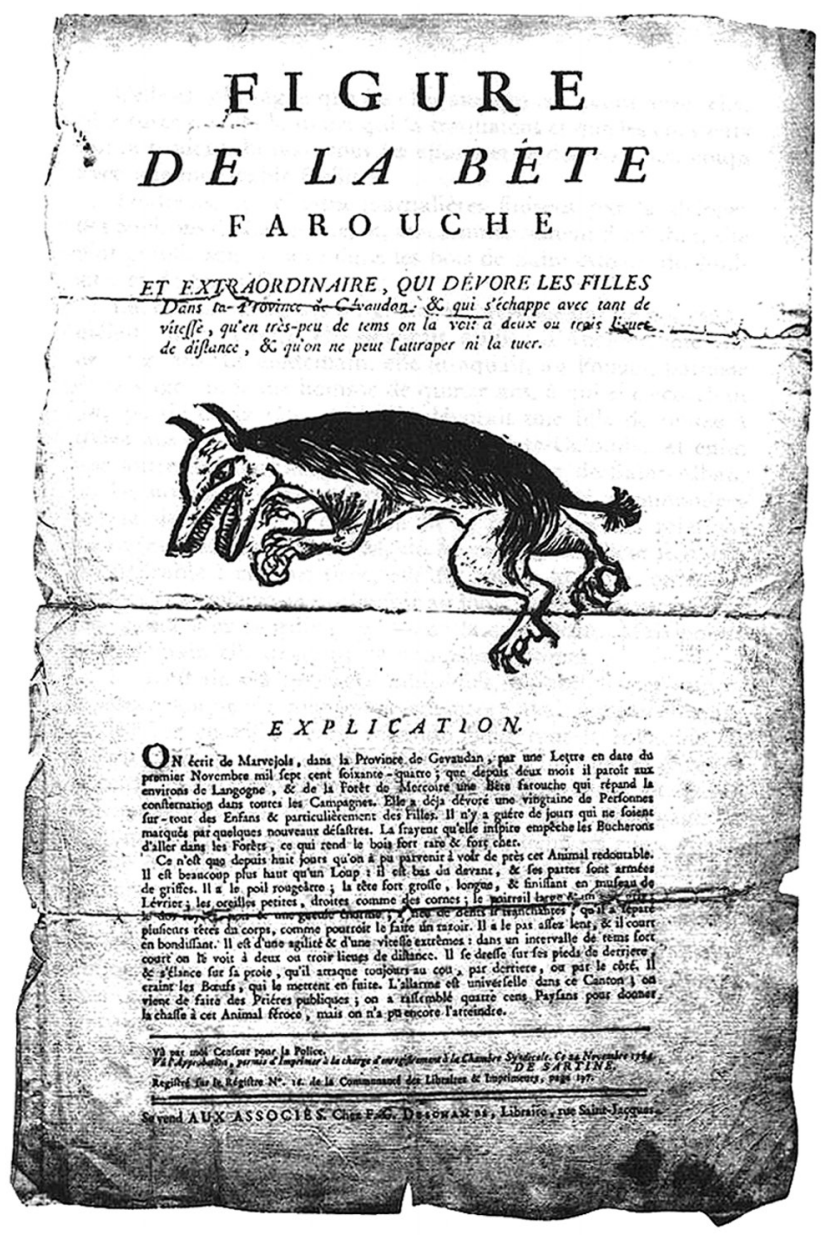

Figure 6 : Figure de la Bête farouche Occasionnel de F.-G. Deschamps, Paris, 1764 Fonds privé

538. La formule «inutile au monde» apparaît dès le Moyen Âge pour désigner les vagabonds, les chômeurs et les salariés non propriétaires. 


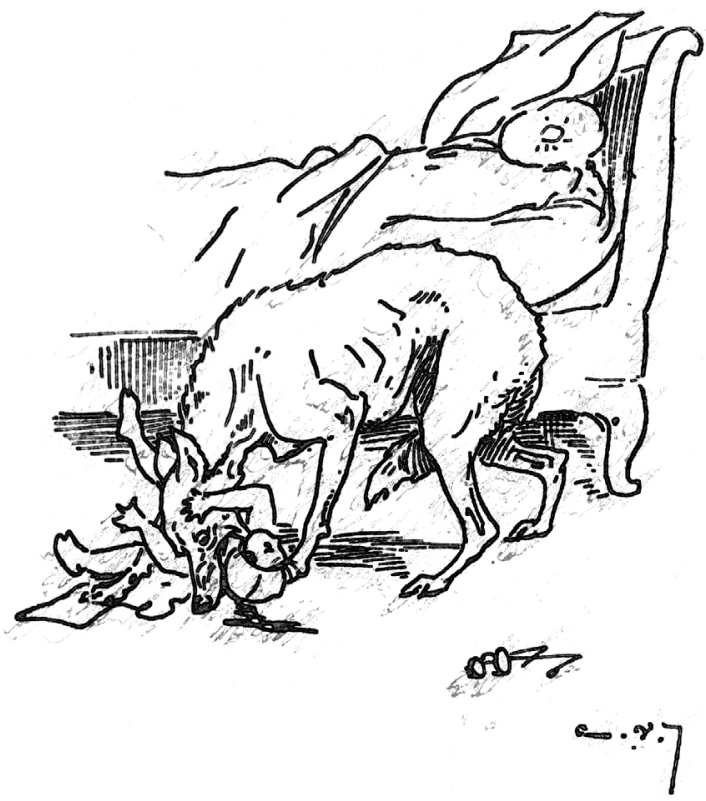

Figure 7 : Les Contes de Perrault

Henri Laurens Éditeur, Paris, 1900 : Le Petit Chaperon rouge, illustrations d'Auguste Vimar

Fonds privé 